\title{
Short-chain fatty acid and vitamin production potentials of Lactobacillus isolated from fermented foods of Khasi Tribes, Meghalaya, India
}

\author{
Subrota Hati ${ }^{1} \cdot$ Maulik Patel $^{1} \cdot$ Birendra K Mishra $^{2} \cdot$ Sujit Das $^{2}$ \\ Received: 28 March 2019 / Accepted: 10 July 2019 / Published online: 22 July 2019 \\ (C) Università degli studi di Milano 2019
}

\begin{abstract}
Purpose Vitamins and SCFA (short-chain fatty acids) production from Lactobacillus isolates are studied due to its health benefits to the human hosts. Lactobacillus strains are widely used in fermented foods, and few of them are reported with vitamin and SCFA production potential. Therefore, in the present study, vitamins and SCFA production capability of isolates were studied to find the potent Lactobacillus cultures for value-added functional food product development.

Methods Five Lactobacillus strains, i.e., KGL2, KGL3A, KGL4, RNS4, and WTS4, were isolated from rice-based traditional fermented foods of Garo Hills, Meghalaya, India. All the well grown isolates were morphologically, physiologically, and genetically characterized. Then, vitamins and SCFA were estimated using HPLC based methods. Vitamins produced in vitamins free assay medium and SCFA in milk medium are produced by Lactobacillus.

Results Lactic acid bacteria produce essential vitamins like riboflavin, folate, cobalamin, and SCFA which have health impacts (anti-obesity, anti-diabetics, anti-microbial, and other chronic diseases prevention) to the host. These vitamins are essential for cellular and metabolic growth of living system. In the study, five potent Lactobacillus isolates viz., KGL2 (Lactobacillus fermentum), KGL3A (Lactobacillus plantarum), KGL4 (Lactobacillus fermentum), RNS4 (Lactobacillus rhamnosus), and WTS4 (Lactobacillus fermentum) were considered for vitamins $\left(\mathrm{B}_{2}, \mathrm{~B}_{12}\right.$, and $\left.\mathrm{B}_{9}\right)$ and SCFA productions (lactate, butyrate, and acetate). However, KGL3A had shown highest $\mathrm{B}_{2}$ production $(0.7 \mu \mathrm{g} / \mathrm{ml})$ while KGL2 exhibited maximum $\mathrm{B}_{12}$ production $(0.05 \mu \mathrm{g} / \mathrm{ml})$ after $36 \mathrm{~h}$. Moreover, WTS4 attributed highest folate production $(0.09 \mu \mathrm{g} / \mathrm{ml})$ after $24 \mathrm{~h}$. In addition, RNS4 reported the maximum short-chain fatty acid production $(0.77 \mathrm{~g} / \mathrm{l}$ acetic acid, $0.26 \mathrm{~g} / 1$ lactic acid, and $0.008 \mathrm{~g} / \mathrm{l}$ butyric acid respectively). Conclusions Potent Lactobacillus isolates from traditional fermented foods of Garo Hills, Meghalaya, India (North East Part of India) showed maximum production of $\mathrm{B}_{2}, \mathrm{~B}_{9}$, and $\mathrm{B}_{12}$ as well as short-chain fatty acids and could be used for their application as health beneficial functional fermented dairy products.
\end{abstract}

Keywords Lactobacillus $\cdot$ Probiotics $\cdot$ Short-chain fatty acids · Vitamins

Subrota Hati and Maulik Patel contributed equally to this work.

Electronic supplementary material The online version of this article (https://doi.org/10.1007/s13213-019-01500-8) contains supplementary material, which is available to authorized users.

Subrota Hati

subrota_dt@yahoo.com

1 Dairy Microbiology Department, SMC College of Dairy Science, AAU, Anand, Gujarat, India

2 Department of RDAP, North Eastern Hill University, Tura Campus, Tura, Meghalaya, India

\section{Introduction}

Microorganisms are natural resource of diverse metabolites (vitamins, essential amino acids, organic acids, peptides), which might be strain specific or species specific. Use of these value-added characteristics microbes as feed additives has increased its demands due to ease of production and health benefits. Vitamins are vital micronutrients for every living cell acting as precursors or participating in many important enzymatic reactions or even in electron transport chain. Microorganisms can generally biosynthesize B group vitamins as per their requirements while humans cannot produce and hence they have to depend on external sources to fulfill their daily requirement (Leblanc et al. 2011). Vitamin- 
producing gut microbiome can synthesize and supply vitamins to the human hosts (Hill 1997). Therefore, scientists are working on finding the novel lactic acid bacteria which are having generally recognized as safe (GRAS) status and can also synthesize vital vitamins and other biomolecules. In the study, we have attempted to isolate lactic acid bacteria (LAB) from rice-based traditional fermented foods of northeast region of India. This area belongs to Garo tribes, and therefore, many traditional healthy fermented foods specific to Garo tribes are available (Kumar et al. 2012; Goswami et al. 2017). Chyne et al. (2017) reported that malnutrition problems of children along with deficiencies in micronutrients (majorly in B-group vitamins) are higher in numbers among the Khasi tribes residing in West Khasi Hills District of Meghalaya due to deficiency of essential micronutrients. Although there is availability of both cultivable and broader wild food resources in Khasi Hills, but nutritional anemia is majorly affecting these areas because of deficiency in iron, folate, and vitamins $\mathrm{A}, \mathrm{B}_{2}, \mathrm{~B}_{6}$, and $\mathrm{B}_{12}$. Not only in northeastern states, there are a huge number of vitamin $B_{12}$ deficiencies among Indian population. The prevalence of folate deficiency is minimal as compared to $\mathrm{B}_{12}$. However, $\mathrm{B}_{12}$ deficiency is more prevalent among the children and adolescents (Toteja and Gonmei 2018). Therefore, we are looking to isolate the indigenous potential microorganisms (GRAS status) with vitamins producing ability in fermented foods. Eastern states of India including Meghalaya countless diverse fermented rice-based food items locally known as ki kpu, putharo, pusyep, pumaloi, pusaw, kanjika, kimoto, and various rice-based beverages are being used since ancient time, which might be good source of edible microbes such as LAB (Lactobacillus johnsonii, Lactobacillus fermentum) with unique characteristics like anti-bacterial potentials (Takahashi 2014; Murugan 2018).

The genus Lactobacillus is a group of lactic acid bacteria which plays an important role in human gut microbiota and also found as active component in associated foods. Some Lactobacillus strains have been exploited for the development of novel functional foods by producing and or releasing the important metabolites. Genome analysis of various LAB species has shown that habitat-specific gene addition and deletion takes place to adapt the surrounding territory (Goh 2009). However, such novel trait specific to strains has to be identified from diverse natural niches and then to be selected for their novel functional and technological attributes. Several LAB species such as Lactococcus lactis, Lactobacillus gasseri, and Lactobacillus reuteri and Bifidobacterium are reported for vitamins and SCFA production (Thirabunyanon et al. 2008; Ventura et al. 2009; Papagianni 2012). Nonetheless, these unique characteristics might help LAB to niche specific survival (gut, diary food) and stimulate interactions with surrounding environments (Besten et al. 2013). Vitamins are vital nutrient of human body for growth and various metabolic activities. However, due to inefficiency of most vitamin synthesis, humans take them as supplementary to the food in terms of plant origin (source of vitamins A, C, $\mathrm{D}, \mathrm{E}, \mathrm{K}$ ) foods or microbial origin (source of vitamin B complex) foods. Supplementation of vitamins of microbial origin has recently gained much attention, and much research is going on to identify the biosynthetic pathways of these vitamins (Patel et al. 2013). B group vitamins are majorly involved in food related energy metabolism; therefore, vitamin Bproducing food-grade microbe identification and development of that microbe containing food are in demand. Vitamin $\mathrm{B}_{12}$, folate-, and riboflavin-producing LAB incorporation into fermented milk, soy milk, or yogurt could increase the vitamin concentration. The supplement of deficient vitamins to the body through foods is the extra advantage to the host (Molina et al. 2012; Gu et al. 2015). Riboflavin is a precursor for flavin mono-nucleotide (FMN) and flavin adenine dinucleotide (FAD) which plays major role in cellular metabolism, and it is reported to produce by the gut microbiome (Hill 1997). Folic acid is the one of the key materials for DNA and RNA biosynthesis and routine metabolic activities of cell; hence, supplementation of folate in food has many advantages such as reduce birth defects and also blood pressure in adults. Dairy product with the value-added folate has been reported; however, it has been shown that some industrially important strains of LAB (L. lactis, Lactobacillus acidophilus, and Lactobacillus plantarum) are responsible behind it (LeBlanc et al. 2011). Cobalamin, which is another essential vitamin of B-complex, works as cofactor in DNA synthesis, hemoglobin synthesis, and various fatty acids and amino acid metabolisms. Very few archaea and bacteria able to produce it and only few LAB can produce it (Bhushan et al. 2016). Santos et al. (2008) reported vitamin $\mathrm{B}_{12^{-}}$and $\mathrm{B}_{9}$-producing strain L. reuteri JCM11112 in fermented milk.

Apart from production of vitamins, recently, LAB are getting more attention because of their organic acid production which also has different therapeutic applications such as antiobesity and anti-diabetic (Salazar et al. 2011). Anti-microbial properties of lactic acid produced by LAB are well reported (Miquel et al. 2013; Mieszkin et al. 2017). Organic acids come under SCFA; mainly, acetate, propionate, and butyrate are vital for maintaining the health of the host when they are available in adequate amounts. SCFA exerts major role in glucose, cholesterol, and lipids metabolism and related metabolic disorders (Besten et al. 2013). As a consequence, it can affect the insulin level, sugar level, and weight of individual (Kimura et al. 2014). Moreover, role of SCFA in types 2 diabetes and obesity control was reported (Cani 2013). Moreover, SCFA roles in anti-inflammation and anti-cancer is reported by the study of Faecalibacterium prausnitzii (a butyrate producer), the leading anti-inflammatory commensal bacterium recognized on the basis of human clinical data of the human intestinal microbiota (Miquel et al. 2013; Chen and Vitetta 2018), where role of $F$. prausnitzii strain A2-165 and 
its culture supernatant was reported to protect against 2,4,6trinitrobenzenesulfonic acid (TNBS)-induced colitis in mice. In the present study, we evaluated the vitamins and organic acids producing ability of LAB (KGL2, KGL3A, KGL4, RNS4, and WTS4) isolated from fermented foods of Garo Hills of Meghalaya, India. The strains were examined for their $\mathrm{B}_{2}, \mathrm{~B}_{9}$, and $\mathrm{B}_{12}$ vitamin production as well as SCFA production (acetic acid, lactic acid, and butyric acid) ability precisely, using high-performance liquid chromatography (HPLC). These Lactobacillus isolates could be used for the production of SCFA in fermented foods for the value addition to the traditional fermented foods with various health benefits associated with SCFA to the consumers. Certain LAB can biosynthesize B group vitamins for their growth and metabolic activities (Hill 1997; Leblanc et al. 2011; Thakur and Tomar 2015). These strains can be used for the development of fermented foods to improve vitamin availability along with the beneficial bacteria.

\section{Materials and methods}

\section{Chemicals and reagents}

All the selective media as well as vitamin production media were purchased from Himedia, India. The HPLC standards for vitamins $\left(\mathrm{B}_{2}, \mathrm{~B}_{9}\right.$, and $\left.\mathrm{B}_{12}\right)$ and SCFA (acetic, lactic, and butyric acid) were purchased from Sigma-Aldrich, India.

\section{LAB isolates}

Garo Hills is tribal area of north-eastern part of India. The tribes residing in these regions are consuming various ricebased fermented beverages as traditional medicines and energy drink in their daily diets. Therefore, we had isolated several $\mathrm{LAB}$ from the fermented rice beverages for their functional studies. The food samples from various fermented rice-based beverages were collected, serially diluted, and plated on Lactobacillus selective agar medium, i.e., MRS medium (HiMedia, India). The grown LAB were purified and examined for morphological and biochemical parameters (API Kit, Biomerieux, Germany). Among them, five isolated LAB were used in present study for their potential SCFA and vitamin production potential determination. Five bacteria, i.e., KGL2, KGL3A, KGL4, RNS4, and WTS4, were isolated from rice-based traditional fermented foods of Garo Hills, Meghalaya, India. The isolates were morphologically and physiologically examined. In addition, the isolates were biochemically examined for catalase activity by inoculating in hydrogen peroxide solution. All the purified cultures were further identified based on $16 \mathrm{~S}$ rDNA-based molecular identification technique. The isolates were grown in $5 \mathrm{ml}$ MRS broth at $37{ }^{\circ} \mathrm{C}$ overnight. The DNA was extracted with DNA isolation kit procured from Genetix India Limited following manufacturer's instruction. The DNA was purified and amplified using $16 \mathrm{~S}$ ribosomal DNA primer 27F (AGAGTTTG ATCMTGGCTCAG) and 519R (GWATTACCGC GGCKGCTG). For pcr amplification, methodology opted from Patel and Patel (2015). Amplified product was sequenced, and nucleotide sequences were retrieved. Then, nucleotide sequences were matched with NCBI BLAST database for the genus and species identification. All the sequence of selected isolates was deposited in NCBI-GenBank along with accession numbers.

\section{Determination of vitamin $B_{2}$ and $B_{12}$ productions}

Vitamin $\mathrm{B}_{2}$ and $\mathrm{B}_{12}$ productions were determined using a microbiological assay as described by Taranto et al. (2003) with some modifications. LAB isolates were inoculated in vitamin $\mathrm{B}_{2}-$ and $\mathrm{B}_{12}$-free assay medium (HiMedia, India) and subcultured three times in the same medium. Cells were incubated in $15 \mathrm{ml}$ of the defined medium at $37^{\circ} \mathrm{C}$ for 12,24 , 36 , and $48 \mathrm{~h}$ and were harvested and washed thrice with $0.1 \mathrm{M}$ phosphate buffer, $\mathrm{pH}$ 7.0. Then, washed cells were suspended in $1 \mathrm{ml}$ of extraction buffer $\left(0.1 \mathrm{M} \mathrm{Na}_{2} \mathrm{HPO}_{4}[\mathrm{pH} 4.5\right.$ using citric acid], $0.005 \% \mathrm{KCN}$ ) and disrupted the cells at $95{ }^{\circ} \mathrm{C}$ for $30 \mathrm{~min}$, followed by vigorous vortexing for $1 \mathrm{~min}$ and centrifuged at $10,000 \times g$ for $10 \mathrm{~min}$. After centrifugation, the supernatant was collected and passed through $0.45-\mu$ syringe filter. Then, the supernatant was analyzed further through HPLC for $\mathrm{B}_{2}$ and $\mathrm{B}_{12}$ productions. In HPLC analysis, 20- $\mu$ l filtrate was injected in HPLC system (LC-10, Shimadzu, Japan) using microinjector for evaluation of $B_{2}$ and $B_{12}$. An isocratic HPLC system was fitted with RP18 endcapped column, LiChroCART column $(250 \times 4.6 \mathrm{~mm})$ (Chromolith-Merck), and a Guard column $(40 \times 4 \mathrm{~mm})$. Sample was loaded using Hilton injector with $20 \mu$ loop. The column was washed twice with distilled water to remove salts and other contaminants for $2 \mathrm{~h}$. After the cartridge was washed with water, the cobalamin was eluted with volume of $50 \%$ acetonitrile with flow rate of $0.3 \mathrm{ml} / \mathrm{min}$ and the oven temperature was kept at $40{ }^{\circ} \mathrm{C}$. Absorbance of elute was monitored at $284 \mathrm{~nm}$ using UV detector.

\section{Determination of folate $\left(B_{9}\right)$ production}

Folate production of the selected $L A B$ strains was determined by a microbiological assay as described by Panda et al. (2018) with some modifications. LAB isolates were inoculated in folate free assay medium (HiMedia, India) and subcultured three times in the same medium. Cells incubated in $15 \mathrm{ml}$ of the defined medium at $37{ }^{\circ} \mathrm{C}$ for $12,24,36$, and $48 \mathrm{~h}$ were harvested and washed thrice with $0.1 \mathrm{M}$ phosphate buffer, $\mathrm{pH}$ 7.0. Washed cells were resuspended in $1 \mathrm{ml}$ of extraction buffer (20 mM sodium phosphate buffer, with $\mathrm{pH}$ 6.2) and 
disrupted at $95^{\circ} \mathrm{C}$ for $30 \mathrm{~min}$, followed by vigorous vortexing for $1 \mathrm{~min}$, and centrifuged at $10,000 \times \mathrm{g}$ for $10 \mathrm{~min}$. After centrifugation, the supernatant was collected and passed through $0.45-\mu$ syringe filter. The collected supernatant was analyzed through HPLC for folate estimation. Five percent of acetonitrile in $20 \mathrm{mM}$ sodium phosphate buffer, with $\mathrm{pH} 6.2$ used as mobile phase and flow rate was $1 \mathrm{ml} / \mathrm{min}$. A UVVisible detector was used at $280 \mathrm{~nm}$ (Panda et al. 2018.

\section{Determination of SCFA production}

SCFA produced by LAB isolates were measured using HPLC system suggested by LeBlanc et al. (2017) with some modification. The active bacterial strain was inoculated in $10 \mathrm{ml}$ sterilized skimmed milk and incubated for $24 \mathrm{~h}$ at $37^{\circ} \mathrm{C}$. After $24 \mathrm{~h}, 5$-ml sample was mixed with $45 \mathrm{ml}$ water and vortexed for $5 \mathrm{~min}$. After vortexing, samples were allowed to settle for 10 min and filtered by Whatman paper no. 42. The filtered samples were further passed through $0.45-\mu$ syringe filter and injected into HPLC system. For HPLC analysis, the column was washed twice with $0.01 \%$ phosphoric acid to remove salts and other contaminants. After the cartridge was washed, the organic acid was eluted with $0.01 \%$ phosphoric acid with flow rate of $0.5 \mathrm{ml} / \mathrm{min}$ and the oven temperature was kept at $40^{\circ} \mathrm{C}$. Absorbance of elute was monitored at $210 \mathrm{~nm}$.

\section{Statistical analysis}

All data presented here are as means $( \pm \mathrm{SEM})$ of three replicates $(n=3)$. The vitamins and organic acid concentrations obtained by HPLC were analyzed using one-way ANOVA with Bonferroni posttest. $P$ values less than 0.05 were considered significant. For graphical presentation and data analysis, Origin (version 8.0) was used.

\section{Results and discussion}

\section{Isolation and identification of Lactobacillus strains}

Five isolates viz., KGL4, RNS4, WTS4, KGL2, and KGL3A were considered for vitamins and SCFA productions. The bacterial isolates were physiologically, morphologically, and biochemically examined for purity and other parameters (Table 1). All the bacterial isolates were preliminary examined for toxicity and pathogenicity which confers nonharmful characteristics of all isolates. Identification of LAB species was also carried out by 16SrRNA gene amplification using PCR method followed by sequencing of PCR product. Based on sequencing analysis through NCBI blast, the identified LAB species are presented in Table 1, with respective accession numbers. Moreover, the derived phylogenetic tree of isolates along with their closely related strains was given in Fig. 1. The phylogenetic tree divides all 5 isolates in two major clusters; one cluster is of $L$. fermentum isolates and their closely related L. fermentum strains from NCBI database, while other cluster is subdivided into two subclusters describing one cluster has L. plantarum and associated strains and other cluster has Lactobacillus rhamnosus and associated strains. The phylogenetic tree suggests each isolate is genetically and evolutionary distinct from other isolates.

\section{Vitamin $B_{2}$ production of the Lactobacillus strains}

Riboflavin is important for cell metabolic activities particularly in oxidation-reduction reactions and cell growth. The microbiological assay with chemically defined $\mathrm{B}_{2}$-free medium has been used for the riboflavin production for the five isolates. KGL3A exhibited highest $B_{2}$ production $(0.72 \mu \mathrm{g} / \mathrm{ml})$ after $36 \mathrm{~h}$. While RNS4 reported maximum $\mathrm{B}_{2}$ production $(0.55 \mu \mathrm{g} / \mathrm{ml})$ after $24 \mathrm{~h}$ followed by decline in vitamin in $36 \mathrm{~h}$ and $48 \mathrm{~h}$ respectively. But WTS4, KGL2, and KGL4 also produced 0.3 to $0.5 \mu \mathrm{g} / \mathrm{ml}$ in 24 to $36 \mathrm{~h}$ (Fig. 2). In initial, 12-h cultures showed no or very minute riboflavin production followed by gradual increase in riboflavin production. However, RNS4 showed production up to $24 \mathrm{~h}$ followed by decrease in riboflavin concentration, while KGL4, WTS4, KGL2, and KGL3A produced riboflavin up to $36 \mathrm{~h}$, followed by decreasing the content after $48 \mathrm{~h}$. The increase in concentration in $\log$ phase and early stationary phase is associated with major role in cell metabolic activities where riboflavin could be utilized by microbes for their multiplication and growth (Kaprasob et al. 2018). Guru and Viswanathan (2013) had reported similar results in their experiments with L. acidophilus and L. lactis fermented whey and skim milk. They reported higher $B_{2}(2930 \mu \mathrm{g} / \mathrm{l}$ and $2610 \mu \mathrm{g} / \mathrm{l}$ respectively) production in whey compared to skimmed milk. In addition, riboflavin production in MRS medium was reported by Thakur and Tomar (2015) with $2.13 \mathrm{mg} / \mathrm{l}$ and $2.36 \mathrm{mg} / \mathrm{l}$ of riboflavin by strain KTLF1 (L. fermentum) and KTLP13 (L. plantarum) respectively. The major objective of this work was to study the riboflavin production potential of isolates and their use in food to complement the daily needs of riboflavin. Likewise, approach was advocated by Russo et al. (2014) for administration of higher riboflavin producing $L$. fermentum PBCC 11.5 and its parental strain to fortify bread and achieved from 3.3 to $7.0 \mu \mathrm{g} / \mathrm{g}$ riboflavin in bread.

\section{Vitamin $\mathbf{B}_{\mathbf{9}}$ productions of the Lactobacillus strains}

Preliminary, folate producing potential was analyzed by chemically defined folate free medium where all the five isolates shown folate production potential. In the study, WTS4 produced $0.092 \mu \mathrm{g} / \mathrm{ml}$ folate after $24 \mathrm{~h}$ and decreasing the contents after $36 \mathrm{~h}$. KGL2, KGL3A, KGL4, and RNS4 showed folate production in the range from 0.05 to 
Table 1 List of bacterial cultures used in the study with biochemical characteristics

\begin{tabular}{|c|c|c|c|c|c|c|c|c|}
\hline $\begin{array}{l}\text { Culture } \\
\text { code }\end{array}$ & Species & $\begin{array}{l}\text { Accession } \\
\text { no. }\end{array}$ & $\begin{array}{l}\text { Morphology (Gram } \\
\text { reaction and shape) }\end{array}$ & $\begin{array}{l}\text { Growth against } \\
6.5 \% \mathrm{NaCl}\end{array}$ & $\begin{array}{l}\text { Catalase } \\
\text { test }\end{array}$ & $\begin{array}{l}\text { Hemolytic } \\
\text { test }\end{array}$ & $\begin{array}{l}\text { Dnase } \\
\text { test }\end{array}$ & $\begin{array}{l}\text { Susceptibility to } \\
\text { antibiotics (Amp, } \\
\text { Tet, ERY, Kan, } \\
\text { Met) }\end{array}$ \\
\hline KGL4 & L. fermentum & MF951099 & Gram + , short road & Negative & Negative & Negative & Negative & Susceptible \\
\hline RNS4 & L. rhamnosus & MG027692 & Gram +, short road & Negative & Negative & Negative & Negative & Susceptible \\
\hline WTS4 & L. fermentum & MG027694 & Gram +, short road & Negative & Negative & Negative & Negative & Susceptible \\
\hline KGL2 & L. fermentum & MG561927 & Gram +, short road & Negative & Negative & Negative & Negative & Susceptible \\
\hline KGL3A & L. plantarum & MG722814 & Gram + , short road & Negative & Negative & Negative & Negative & Susceptible \\
\hline
\end{tabular}

Amp ampicillin (10 mcg), Tet tetracycline (30 mcg), ERY erythromycin (15 mcg), Kan kanamycin (30 mcg), Met methicillin (5 mcg)

$0.082 \mu \mathrm{g} / \mathrm{ml}$ after $12 \mathrm{~h}$, followed by decreasing in between 24 and $36 \mathrm{~h}$ (Fig. 3). Microbes synthesize mainly two types of folate, namely 5-methyl tetrahydrofolate (5-MTHF) and tetrahydrofolate (THF). However, all the isolates were producing 5-MTHF during HPLC analysis. Panda et al. (2018) and Gangadharan et al. (2010) reported the 5-MTHF producing LAB. Precisely, L. rhamnosus (IFM-4), L. cremoris (CM22), and L. lactis (CM28) studied with $35 \mathrm{ng} / \mathrm{ml}, 12.5 \mathrm{ng} / \mathrm{ml}$, and $14.2 \mathrm{ng} / \mathrm{ml}$ folate production respectively. The major role of folate is in nucleic acid biosynthesis; hence, it is require in high amount in early log phase. Microbes used in the studies are capable to synthesize their own requirement of folate. In high amount of folate production in early growth phase $(12 \mathrm{~h})$, results can be correlated for nucleic acid synthesis and cell growth while decline with time is associated with less requirement in matured cells. These results clearly exhibited the role of folate in early development of cells and its importance. Sequencing information from the available data revealed that L. johnsonii, L. acidophilus, Lactobacillus salivarius, Lactobacillus brevis, Lactobacillus casei, L. gasseri, L. rhamnosus, and Lactobacillus crispatus lack the genes for folate biosynthesis production while L. lactis, L. plantarum, Lactobacillus sakei, Lactobacillus delbrueckii, L. reuteri, Lactobacillus helveticus, and L. fermentum have folate biosynthesis gene clusters and assume that they could produce folate (Rossi et al. 2011). The four strains used in our studies belong to L. fermentum (KGL2, KGL4, and WTS4) and L. plantarum (KGL3A) which advocate authentication of our results with scientifically reported data elsewhere (Leblanc et al. 2011). Two good folate producers reveled in the study WTS4 and KGL3A could be used in the future for fortification of folate in fermented dairy products.

\section{Vitamin $B_{12}$ production of the Lactobacillus strains}

All the $\mathrm{LAB}$ isolates were grown in vitamin $\mathrm{B}_{12}$-free assay medium, and therefore, HPLC quantification was carried out. HPLC analysis shown KGL2 has highest $0.058 \mu \mathrm{g} / \mathrm{ml} \mathrm{B}_{12}$ production, followed by KGL3A $(0.046 \mu \mathrm{g} / \mathrm{ml})$ after $36 \mathrm{~h}$ of incubation (Fig. 4). Both the reported strains achieved maximum $B_{12}$ production in $36 \mathrm{~h}$ followed by depletion after $48 \mathrm{~h}$. Possible reason is due to the deficient in nutrient concentration leading to reduction in metabolic activity. Similar results of $\mathrm{B}_{12}$ producing $\mathrm{LAB}$ namely $L$. plantarum, $L$. casei, $L$. reuteri, and Lactobacillus coryniformis were reported (Masuda et al. 2012; Gu et al. 2015). While WTS4 had exhibited $0.024 \mu \mathrm{g} / \mathrm{ml} \mathrm{B}_{12}$ production after $24 \mathrm{~h}$, followed by decline in $36 \mathrm{~h}$ and achieved its maximum $\mathrm{B}_{12}$ production $(0.028 \mu \mathrm{g} / \mathrm{ml})$ after $48 \mathrm{~h}$. Moreover, KGL4 and RNS4 have shown sequential increase in vitamin production $(0.023 \mu \mathrm{g} / \mathrm{ml}$
Fig. 1 Phylogenetic tree of LAB isolates with their closest bacteria from NCBI Database

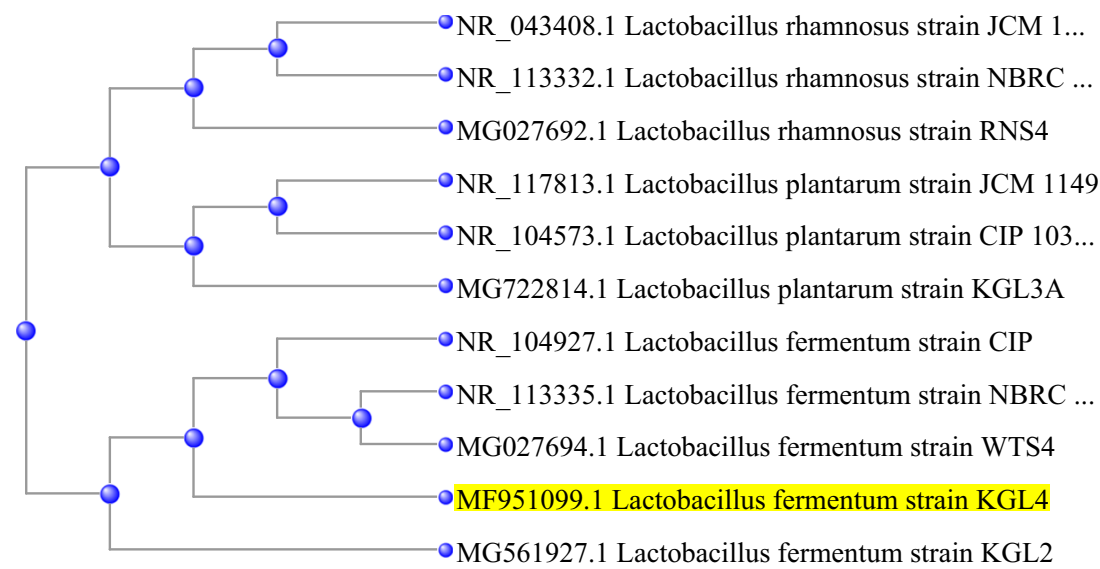


Fig. 2 Vitamin $\mathrm{B}_{2}$ production by Lactobacillus isolates. Means with different letters $(\mathrm{a}, \mathrm{b}, \mathrm{c})$ indicating significant difference $(P<0.05), n=3$, means \pm S.D. a $12 \mathrm{H} \quad \mathbf{H} 24 \mathrm{H} \geqslant 36 \mathrm{H} \quad 348 \mathrm{H}$

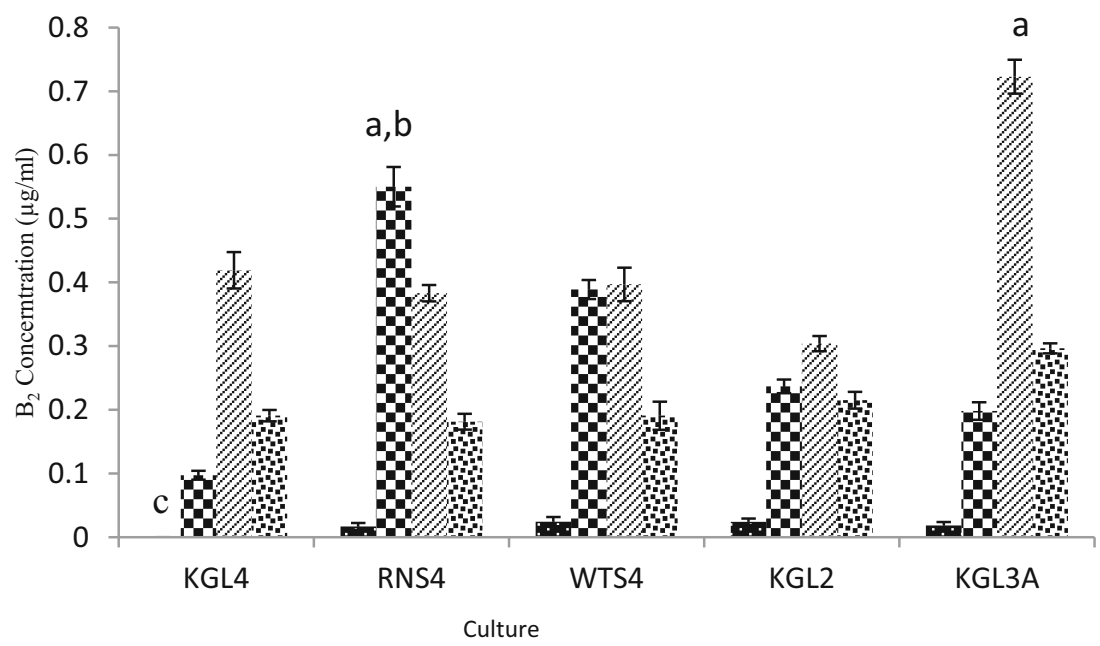

and $0.035 \mu \mathrm{g} / \mathrm{ml}$ respectively) up to $24 \mathrm{~h}$, followed by decreasing after $36 \mathrm{~h}$ and $48 \mathrm{~h}$. However, few vitamins $\mathrm{B}_{12}$ producing $\mathrm{LAB}$ are reported compared to folate or riboflavin production. The first evidence of $\mathrm{B}_{12}$ production in LAB was reported in L. reuteri CRL1908 (Taranto et al. 2003). The chromatographic data of CRL1908 cell extract confirmed the presence of cobalamin like compound and further identified as cobalamin. Recently, during the genome analysis of Lactobacillus rossiae, a complete de novo biosynthesis pathway of vitamin $B_{12}$ was constructed and identified in few microbes (Angelis et al. 2014). Moreover, latest identification of important $\mathrm{B}_{12}$ structural genes (cobT, cbiB and cbiA) and previously known cbiK would further help to the researchers to identify the $\mathrm{B}_{12}$ production mechanism (Bhushan et al. 2016) and also to design strategies to execute overproduction of these vitamins for future application using cloning methods. With increasing the awareness of vitamin $\mathrm{B}_{12}$ related

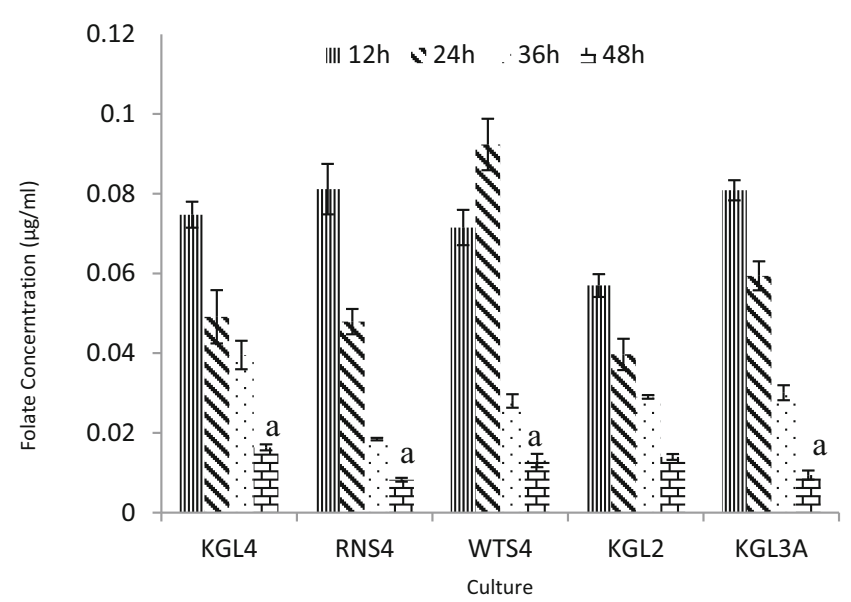

Fig. 3 Vitamin $\mathrm{B}_{9}$ production by Lactobacillus isolates. Means with different letters $(\mathrm{a}, \mathrm{b})$ indicating significant difference $(P<0.05), n=3$, means \pm S.D. deficiencies and consequences to the human health, people are looking for vitamin $\mathrm{B}_{12}$ enriched foods. Therefore, the use of vitamin $\mathrm{B}_{12}$-producing $\mathrm{LAB}$ in fermented or dairy foods could be a good alternative to mitigate $B_{12}$ deficiencies in community.

\section{Determination of SCFA production}

Increasing health awareness have recently exploded the role of SCFA in gastrointestinal tract and associated health benefits (LeBlanc et al. 2017). Therefore, people are looking for products having good sources of health supporting SCFA. Dairy products associated with milk fermentation by LAB are good sources of these organic acids. LAB-fermented products are rich in lactic acid, followed by acetic acid, and also contain minute quantity of propionic acid and butyric acid. Therefore,

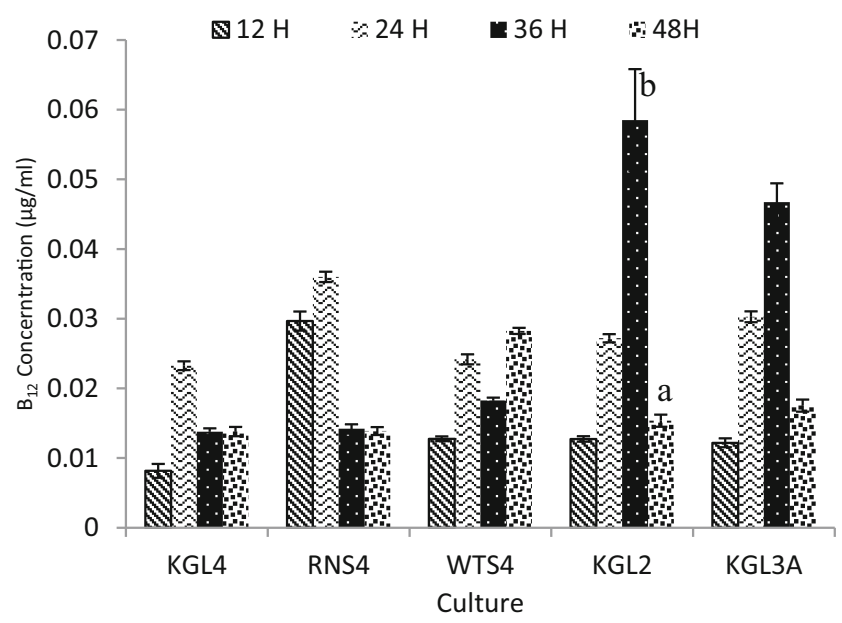

Fig. 4 Vitamin $\mathrm{B}_{12}$ production by Lactobacillus isolates. Means with different letters $(\mathrm{a}, \mathrm{b})$ indicating significant difference $(P<0.05), n=3$, means \pm S.D. 
(a)

Acetic acid

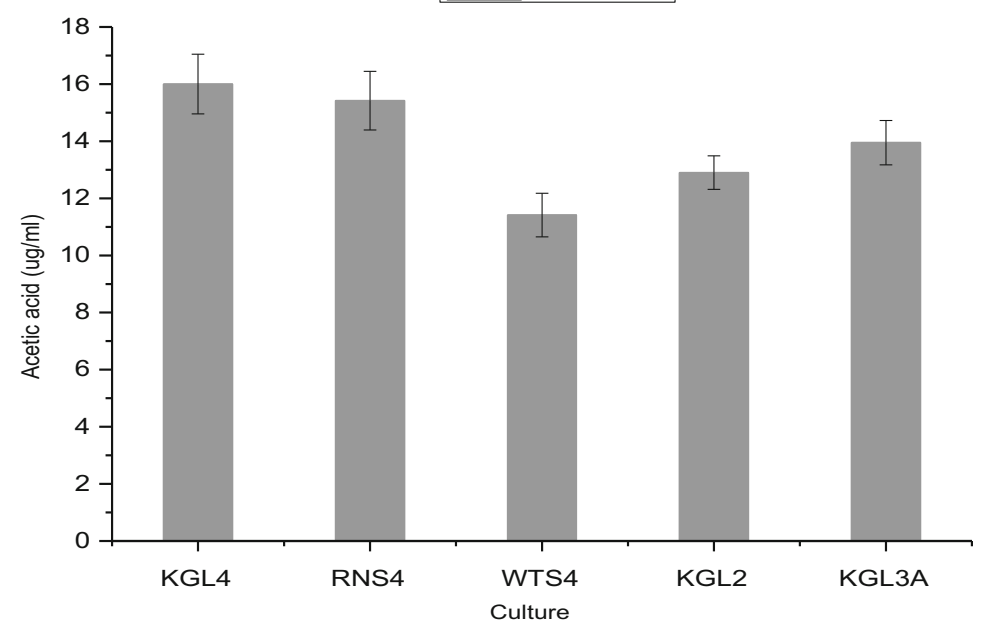

(b)

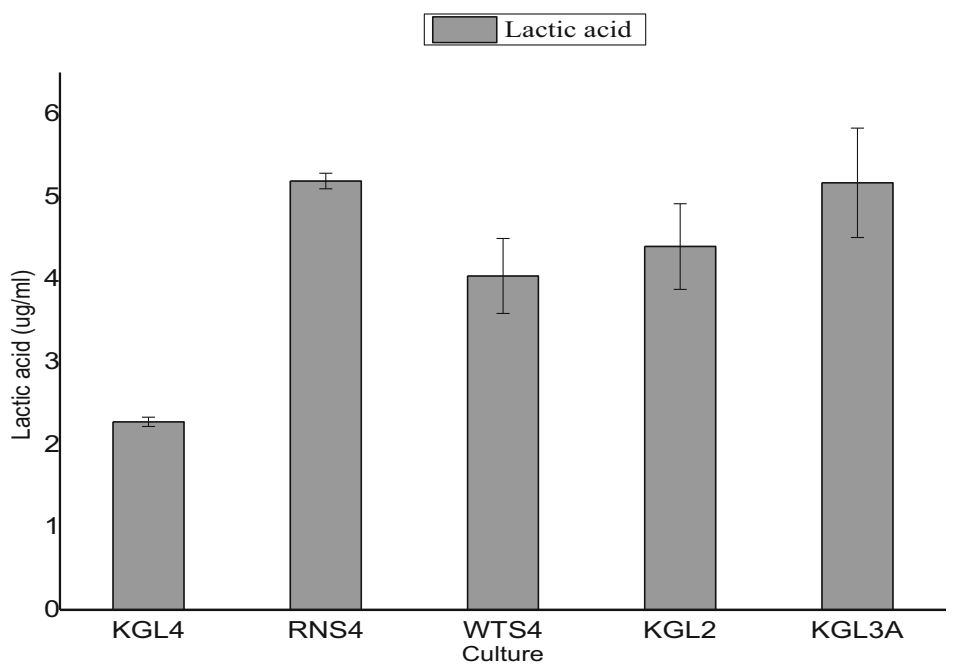

(c)

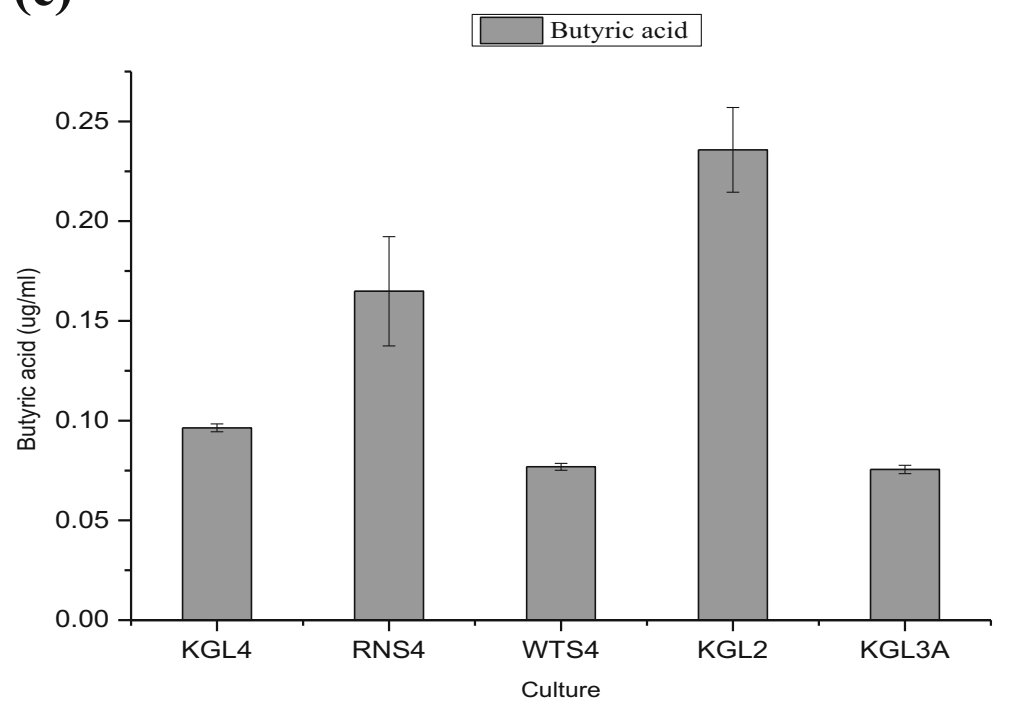

Fig. 5 SCFA production by Lactobacillus isolates after $24 \mathrm{~h}$. a Acetic acid. b Lactic acid. $\mathbf{c}$ Butyric acid $(P<0.05), n=3$, means \pm S.D. 
the SCFA-producing ability of five LAB isolates was studied in this study. RNS4 (L. rhamnosus) showed highest overall SCFA production among all the isolates with $15.41 \mu \mathrm{g} / \mathrm{ml}$ acetic acid (Fig. 5a), $5.18 \mu \mathrm{g} / \mathrm{ml}$ lactic acid (Fig. 5b), and $0.16 \mu \mathrm{g} / \mathrm{ml}$ butyric acid (Fig. $5 \mathrm{c}$ ), followed by KGL2 with $12.9 \mu \mathrm{g} / \mathrm{ml}, 4.39 \mu \mathrm{g} / \mathrm{ml}$, and $0.23 \mu \mathrm{g} / \mathrm{ml}$ acetic acid, lactic acid, and butyric acid respectively. Similar result of SCFA production reported in L. rhamnosus strain $G G$ along with propionic acid $(89 \mu \mathrm{M})$ production in MRS medium (LeBlanc et al. 2017), while KGL4 $(16 \mu \mathrm{g} / \mathrm{ml})$, RNS2 $(5.1916 \mu \mathrm{g} / \mathrm{ml})$, and KGL2 $(0.2516 \mu \mathrm{g} / \mathrm{ml})$ showed maximum acetic acid, lactic acid, and butyric acid production after $24 \mathrm{~h}$. The variation in acid production is particularly strain specific due to inherent potential of each strain at individual level rather than species level (Macfarlane and Macfarlane 2003). Carbohydrate fermentation by LAB can leads to various shortchain fatty acid productions (Pessione 2012). Even in carbon depletion and anaerobic condition, lactic acid can be further converted into acetic acid by several LAB (Oude Elferink et al. 2001). The results showed higher production of acetic acid and it is associated with heterofermentative nature of LAB (Axelsson 2004). Furthermore, the isolation niche (rice-based food) advocates its heterofermentative environment and in agreement of results obtained by Pessione (2012). He reported higher acetic acid and lactic acid production while minute amount of propionic and butyric acid production. Higher level of acetic acid and lactic acid attributes great anti-microbial activity against wide range of bacteria and fungi including food pathogens (Mieszkin et al. 2017). LAB administrations into gut indirectly enhance SCFA production by selectively permitting the growth of SCFA-producing gut microbiota (Seeliger 2002; Belenguer et al. 2006). As the health benefits associated with SCFA were well reported, the administration of SCFA-producing LAB would have added on advantage on individual's health. The recent scientific data suggests that SCFA modulate various health factors including immune cells, adipose tissue, and hepatocyte which have major role in host immunity and obesity (Besten et al. 2013; Bhutia and Ganapathy 2015). The role of butyrate is well studied in ulcerative colitis, by blocking $\beta$-oxidation that inhibits butyrate consumption results in severe ulcers in colon (Roediger and Millard 1995).

\section{Conclusions}

Vitamins and SCFA are healthy metabolites for the human hosts. Production of vitamins and organic acids using Lactobacillus cultures is an alternative source for the development of functional fermented dairy foods. Uses of LAB with extraordinary health benefits have great demands. Therefore, potent Lactobacillus isolates from traditional fermented foods of Garo Hills showed maximum production of $\mathrm{B}_{2}, \mathrm{~B}_{9}$, and $\mathrm{B}_{12}$ as well as short-chain fatty acids. These five Lactobacillus cultures could be used for the development of functional fermented dairy foods.

Funding This research was financed by the Department of Biotechnology, New Delhi, Government of India (Agri/2015/02).

Compliance with ethical standards This article does not contain any studies with human participants or animals performed by any of the authors.

Conflict of interest The authors declare that they have no conflict of interest.

\section{References}

Angelis MD, Bottacini F, Fosso B, Kelleher P, Calasso M, Cagno RD, Ventura M, Picardi E, Sinderen DV, Gobbetti M (2014) Lactobacillus rossiae, a vitamin B12 producer, represents a metabolically versatile species within the genus Lactobacillus. PLoS One 9. https://doi.org/10.1371/journal.pone.0107232

Axelsson L (2004) Lactic acid bacteria: classification and physiology. In: Salminen S, Wright AV, Ouwehand A (eds) Lactic acid bacteria: microbiological and functional aspects, 3rd Edition. Marcel Dekker, New York, pp 1-67. https://doi.org/10.1201/ 9780824752033.ch1

Belenguer A, Duncan SH, Calder AG, Holtrop G, Louis P, Lobley GE, Flint HJ (2006) Two routes of metabolic cross-feeding between Bifidobacterium adolescentis and butyrate-producing anaerobes from the human gut. Appl Environ Microbiol 72:3593-3599. https://doi.org/10.1128/aem.72.5.3593-3599.2006

Besten GD, Eunen KV, Groen AK, Venema K, Reijngoud D-J, Bakker BM (2013) The role of short-chain fatty acids in the interplay between diet, gut microbiota, and host energy metabolism. J Lipid Res 54:2325-2340. https://doi.org/10.1194/jlr.r036012

Bhushan B, Tomar SK, Mandal S (2016) Phenotypic and genotypic screening of human-originated lactobacilli for vitamin B12 production potential: process validation by micro-assay and UFLC. Appl Microbiol Biotechnol 100:6791-6803. https://doi.org/10.1007/ s00253-016-7639-9

Bhutia YD, Ganapathy V (2015) Short, but smart: SCFA train T cells in the gut to fight autoimmunity in the brain. Immunity 43:629-631. https://doi.org/10.1016/j.immuni.2015.09.014

Cani PD (2013) The gut microbiota manages host metabolism. Nat Rev Endocrinol 10:74-76. https://doi.org/10.1038/nrendo.2013.240

Chen J, Vitetta L (2018) Inflammation-modulating effect of butyrate in the prevention of colon cancer by dietary fiber. Clin Colorectal Cancer 17. https://doi.org/10.1016/j.clcc.2018.05.001

Chyne DAL, Meshram II, Rajendran A et al (2017) Nutritional status, food insecurity, and biodiversity among the Khasi in Meghalaya, North-East India. Matern Child Nutr. https://doi.org/10.1111/mcn. 12557

Gangadharan D, Sivaramakrishnan S, Pandey A, Nampoothiri KM (2010) Folate-producing lactic acid bacteria from cow's milk with probiotic characteristics. Int J Dairy Technol 63:339-348. https:// doi.org/10.1111/j.1471-0307.2010.00590.x

Goh YJ (2009) Genomic features of Lactobacillus species. Front Biosci: 1362. https://doi.org/10.2741/3313

Goswami G, Bora SS, Parveen A, Boro RC, Barooah M (2017) Identification and functional properties of dominant lactic acid bacteria isolated from Kahudi, a traditional rapeseed fermented food 
product of Assam, India. J Ethnic Foods 4:187-197. https://doi.org/ 10.1016/j.jef.2017.08.008

Gu Q, Zhang C, Song D, Li P, Zhu X (2015) Enhancing vitamin B12 content in soy-yogurt by Lactobacillus reuteri. Int J Food Microbiol 206:56-59. https://doi.org/10.1016/j.ijfoodmicro.2015.04.033

Guru V, Viswanathan K (2013) Riboflavin production in milk whey using probiotic bacteria-Lactobacillus acidophilus and Lactococcus lactis. Indian J Fundam Appl Life Sci 3:169-176

Hill MJ (1997) Intestinal flora and endogenous vitamin synthesis. Eur J Cancer Prev 6. https://doi.org/10.1097/00008469-19970300100009

Kaprasob R, Kerdchoechuen O, Laohakunjit N, Somboonpanyakul P (2018) B vitamins and prebiotic fructooligosaccharides of cashew apple fermented with probiotic strains Lactobacillus spp., Leuconostoc mesenteroides and Bifidobacterium longum. Process Biochem 70:9-19. https://doi.org/10.1016/j.procbio.2018.04.009

Kimura I, Inoue D, Hirano K, Tsujimoto G (2014) The SCFA receptor GPR43 and energy metabolism. Front Endocrinol 5(85). https://doi. org/10.3389/fendo.2014.00085

Kumar RS, Kanmani P, Yuvaraj N, Paari KA, Pattukumar V, Arul V (2012) Traditional Indian fermented foods: a rich source of lactic acid bacteria. Int J Food Sci Nutr 64:415-428. https://doi.org/10. 3109/096374866.2012.746288

Leblanc J, Laiño J, Valle MJD, Vannini V, Sinderen DV, Taranto M, Sesma F (2011) B-group vitamin production by lactic acid bacteria - current knowledge and potential applications. J Appl Microbiol 111:1297-1309. https://doi.org/10.1111/j.1365-2672.2011.05157.x

Leblanc JG, Chain F, Martín R, Bermúdez-Humarán LG, Courau S, Langella P (2017) Beneficial effects on host energy metabolism of short-chain fatty acids and vitamins produced by commensal and probiotic bacteria. Microb Cell Factories 16. https://doi.org/10. 1186/s12934-017-0691-z

Macfarlane S, Macfarlane GT (2003) Regulation of short-chain fatty acid production. Proc Nutr Soc 62:67-72

Masuda M, Ide M, Utsumi H, Niiro T, Shimamura Y, Murata M (2012) Production potency of folate, vitamin B12, and thiamine by lactic acid bacteria isolated from Japanese pickles. Biosci Biotechnol Biochem 76:2061-2067. https://doi.org/10.1271/bbb.120414

Mieszkin S, Hymery N, Debaets S, Coton E, Blay GL, Valence F, Mounier J (2017) Action mechanisms involved in the bioprotective effect of Lactobacillus harbinensis K.V9.3.1.Np against Yarrowia lipolytica in fermented milk. Int J Food Microbiol 248:47-55. https://doi.org/10.1016/j.ijfoodmicro.2017.02.013

Miquel S, Martín R, Rossi O, Bermúdez-Humarán L, Chatel J, Sokol, Langella P (2013) Faecalibacterium prausnitzii and human intestinal health. Curr Opin Microbiol 16:255-261. https://doi.org/10.1016/j. mib.2013.06.003

Molina V, Médici M, Valdez GFD, Taranto MP (2012) Soybean-based functional food with vitamin B12-producing lactic acid bacteria. J Funct Foods 4:831-836. https://doi.org/10.1016/j.jff.2012.05.011

Murugan B (2018) Antibacterial activity of indigenous fermented rice beverage of West Garo Hills, Meghalaya, India. Int J Fermented Foods 7. https://doi.org/10.30954/2321-712x.01.2018.5

Oude Elferink SJWH, Krooneman J, Gottschal JC, Spoelstra SF, Faber F, Driehuis F (2001) Anaerobic conversion of lactic acid to acetic acid and 1,2-propanediol by Lactobacillus buchneri. Appl Environ Microbiol 67:125-132. https://doi.org/10.1128/aem.67.1.125-132. 2001

Panda SH, Das S, Bal P, Panda SK, Mohanty N (2018) Characterization of novel folate producing Lactobacillus rhamnosus and its appliance in fortification of ragi (Eleusine coracana) gruel. Food Biosci 21: $100-106$
Papagianni M (2012) Metabolic engineering of lactic acid bacteria for the production of industrially important compounds. Computat Structl Biotechnol J 3. https://doi.org/10.5936/csbj.201210003

Patel A, Shah N, Prajapati JB (2013) Biosynthesis of vitamins and enzymes in fermented foods by lactic acid bacteria and related genera a promising approach. Croat J Food Sci Technol 5:85-91

Patel M, Patel H (2015) Isolation and molecular characterization of potential plant growth promoting Bacillus megaterium from capsicum cultivation field. J Ind Pollut Control 31:94-104

Pessione E (2012) Lactic acid bacteria contribution to gut microbiota complexity: lights and shadows. Front Cell Infect Microbiol 2(86). https://doi.org/10.3389/fcimb.2012.00086

Roediger WE, Millard S (1995) Selective inhibition of fatty acid oxidation in colonocytes by ibuprofen: a cause of colitis? Gut 36:55-59. https://doi.org/10.1136/gut.36.1.55

Rossi M, Amaretti A, Raimondi S (2011) Folate production by probiotic bacteria. Nutrients 3:118-134. https://doi.org/10.3390/nu3010118

Russo P, Capozzi V, Arena MP, Spadaccino G, Dueñas MT, López P et al (2014) Riboflavin-overproducing strains of Lactobacillus fermentum for riboflavin-enriched bread. Appl Microbiol Biotechnol 98:3691-3700. https://doi.org/10.1007/s00253-0135484-7

Salazar N, Binetti A, Gueimonde M, Alonso A, Garrido P, Rey CGD et al (2011) Safety and intestinal microbiota modulation by the exopolysaccharide-producing strains Bifidobacterium animalis IPLA R1 and Bifidobacterium longum IPLA E44 orally administered to Wistar rats. Int J Food Microbiol 144:342-351. https://doi. $\operatorname{org} / 10.1016 / j$. .jffoodmicro.2010.10.016

Santos F, Wegkamp A, Vos WMD et al (2008) High-level folate production in fermented foods by the B12 producer Lactobacillus reuteri JCM1112. Appl Environ Microbiol 74:3291-3294. https://doi.org/ 10.1128/aem.02719-07

Seeliger S (2002) Energetics and kinetics of lactate fermentation to acetate and propionate via methylmalonyl-CoA or acrylyl-CoA. FEMS Microbiol Lett 211:65-70. https://doi.org/10.1016/s0378-1097(02) 00651-1

Takahashi T (2014) Development of fermented rice drink using lactic acid bacteria isolated from Kimoto. J The Brewing Soc Japan 109:705712. https://doi.org/10.6013/jbrewsocjapan.109.705

Taranto MP, Vera JL, Hugenholtz J, Valdez GFD, Sesma F (2003) Lactobacillus reuteri CRL1098 produces cobalamin. J Bacteriol 185:5643-5647. https://doi.org/10.1128/jb.185.18.5643-5647.2003

Thakur K, Tomar SK (2015) Exploring indigenous Lactobacillus species from diverse niches for riboflavin production. Journal of Young Pharmacists 7:122-127. https://doi.org/10.5530/jyp.2015.2.11

Thirabunyanon M, Boonprasom P, Niamsup P (2008) Probiotic potential of lactic acid bacteria isolated from fermented dairy milks on antiproliferation of colon cancer cells. Biotechnol Lett 31:571576. https://doi.org/10.1007/s10529-008-9902-3

Toteja G, Gonmei Z (2018) Micronutrient status of Indian population. Indian J Med Res 148:511. https://doi.org/10.4103/ijmr.ijmr_1768_ 18

Ventura M, Turroni F, Zomer A, Foroni E, Giubellini V, Bottacini F, Sinderen DV (2009) The Bifidobacterium dentium Bd1 genome sequence reflects its genetic adaptation to the human oral cavity. PLoS Genet 5. https://doi.org/10.1371/journal.pgen.1000785

Publisher's note Springer Nature remains neutral with regard to jurisdictional claims in published maps and institutional affiliations. 